\title{
CELL CYTOSKELETAL CHANGES EFFECTED BY STATIC COMPRESSIVE STRESS LEAD TO CHANGES IN THE CONTRACTILE PROPERTIES OF TISSUE REGENERATIVE COLLAGEN MEMBRANES
}

Kris Gellynck ${ }^{1}$, Rishma Shah ${ }^{1}$, Dan Deng ${ }^{2}$, Mohamed Parkar ${ }^{1}$, Wei Liu ${ }^{2}$, Jonathan C. Knowles ${ }^{1,3, *}$ and Paul Buxton ${ }^{1}$

${ }^{1}$ Division of Biomaterials and Tissue Engineering, UCL Eastman Dental Institute, London, UK

${ }^{2}$ Shanghai 9th People's Hospital, Shanghai Second Medical University, Shanghai, China

${ }^{3}$ WCU Research Centre of Nanobiomedical Science, Dankook University, Cheonan-si, Chungnam, South Korea

\begin{abstract}
Static compressive stress can influence the matrix, which subsequently affects cell behaviour and the cell's ability to further transform the matrix. This study aimed to assess response to static compressive stress at different stages of osteoblast differentiation and assess the cell cytoskeleton's role as a conduit of matrix-derived stimuli. Mouse bone marrow mesenchymal stem cells (MSCs) (D1 ORL UVA), osteoblastic cells (MC3T3-E1) and postosteoblast/pre-osteocyte-like cells (MLO-A5) were seeded in hydrated and compressed collagen gels. Contraction was quantified macroscopically, and cell morphology, survival, differentiation and mineralisation assessed using confocal microscopy, alamarBlue ${ }^{\circledR}$ assay, real-time quantitative reverse transcription polymerase chain reaction (RT-qPCR) and histological stains, respectively. Confocal microscopy demonstrated cell shape changes and favourable microfilament organisation with static compressive stress of the collagen matrix; furthermore, cell survival was greater compared to the hydrated gels. The stage of osteoblast differentiation determined the degree of matrix contraction, with MSCs demonstrating the greatest amount. Introduction of microfilament disrupting inhibitors confirmed that prestress and tensegrity forces were under the influence of gel density, and there was increased survival and differentiation of the cells within the compressed collagen compared to the hydrated collagen. There was also relative stiffening and differentiation with time of the compressed cell-seeded collagen, allowing for greater manipulation. In conclusion, the combined collagen chemistry and increased density of the microenvironment can promote upregulation of osteogenic genes and mineralisation; MSCs can facilitate matrix contraction to form an engineered membrane with the potential to serve as a 'pseudo-periosteum' in the regeneration of bone defects.
\end{abstract}

Keywords: compression; tensegrity; cell shape; cytoskeleton; bone; collagen gel; extracellular matrix; barrier membrane; tissue regeneration; differentiation; contraction.

*Address for correspondence:

Professor J. C. Knowles

Division of Biomaterials and Tissue Engineering

UCL Eastman Dental Institute

256 Gray's Inn Road

London, WC1X 8LD, UK

Telephone Number: 44 (0) 2034561189

FAX Number: 44 (0) 2034561227

E-mail: j.knowles@ucl.ac.uk

\section{Introduction}

Bone defects are currently managed using autografts or allografts. However, there are associated limitations including the lack of available tissue, donor site morbidity and immunosuppression (Perry, 1999). Tissue engineered bone substitutes have the potential to overcome many of these disadvantages, and studies undertaken have used different approaches with varying degrees of success (Braddock et al., 2001; Jakob et al., 2012; Rose and Oreffo, 2002). For example, the challenge of restoring defects using growth factors (e.g. bone morphogenetic proteins) is optimal delivery in vivo (Itoh et al., 2001) and biomaterials used to mimic characteristics of the natural bone extracellular matrix (ECM), such as poly(lactic) and poly(glycolic) acid, lack the necessary mechanical competence (Link et al., 2006).

Type I collagen has been used widely in bone tissue engineering, because the chemical composition represents the major component of natural bone extracellular matrix (ECM) (Liu et al., 1995). But, once again, the structure and microenvironment is not always easily represented (Abou Neel et al., 2006; Brown et al., 2005; Cheema et al., 2003; Cheema et al., 2007), and cells as tensegrity structures are influenced by microenvironmental forces that can lead to positive changes in behaviour. Tensegrity relies upon two components, rigid non-compressible "struts" (the microtubules) and flexible "cables" (actin microfilaments), to which tension can be applied in order to maintain cell shape and tissue structure (Hu et al., 2004; Stamenovic et al., 2002; Stamenovic and Wang, 2000). In addition, cell contractility is due to molecular motors, which are also needed for adhesion maturation and the maintenance of focal complexes and contacts: specifically, non-muscle myosin II is key to the contractility of non-muscle cells and crucial to mechano-sensing and signal transduction (Cai et al., 2006; Straight et al., 2003).

Static compressive stress of cell-seeded hyperhydrated type I collagen gels can lead to a change in the microenvironment and structure to produce tissue-like scaffolds with enhanced biomechanical properties (Bitar et al., 2007; Bitar et al., 2008; Brown et al., 2005; Mudera et al., 2007). In addition to possible changes in cell survival and differentiation, a shift in microfilament and dendrite distribution could lead to a favourable change in the relationship between cell contractility and subsequent contraction of the collagen gel. By increasing the collagen density in this manner and using an appropriate cell density, these scaffolds have the potential to be developed into highly biomimetic cell-seeded membranes leading to successful clinical application (Bitar et al., 2008). For 
example, such an engineered pseudo-periosteal membrane may be successfully used for the management of bone defects whereby cells required in the regenerative process are contained within the defect site.

The overall study hypothesis was that static compressive stress can support the cellular response towards the production of a pseudo-periosteum for future use in the healing of bony defects. This study had three aims:

1. To investigate how change in the physical environment can influence cell response in terms of cell deformation, survival and osteogenic capability.

2. To investigate the response to compression at different stages of osteoblast differentiation (Olson, 2004). The stage of differentiation may influence the response and thus investigation was considered essential in order to confirm the cell type required to maximise the potential clinical use of this engineered construct.

3. To confirm the role of the cell cytoskeleton as a conduit of matrix-derived stimuli by investigating the effects of disabling active contraction within the cell (Rehfeldt et al., 2007). The drug blebbistatin was used as a selective non-muscle myosin II inhibitor that blocks motor activity without affecting actin binding. Additionally, Y-27632, a selective inhibitor of Rho-associated protein kinase p160ROCK, was used as another method to disrupt the cytoskeletalbased tensegrity. The protein kinase is implicated in various cellular functions, including actin cytoskeleton organisation, cell adhesion, cell motility, vascular and smooth muscle contraction and cytokinesis (Takahara et al., 2003; Uehata et al., 1997).

\section{Materials and Methods}

\section{Cell culture}

Mouse bone marrow mesenchymal stem cells (MSCs) (D1 ORL UVA; ATCC, Teddington, UK), mouse osteoblastic cells (MC3T3-E1; LGC Promochem, Teddington, UK) and mouse post-osteoblast/pre-osteocyte-like cells (MLO-A5; ATCC, UK) were used in the investigations. These cells were maintained and expanded for a maximum of 2 passages. D1 cells were cultured in low glucose Dulbecco's modified Eagle medium (LG DMEM; Invitrogen, Paisley, UK) and MC3T3 and MLO-A5 cells were cultured in minimum essential medium ( $\alpha$ MEM; Invitrogen). All media were supplemented with $10 \%$ foetal bovine serum (FBS) (PAA (MC3T3-E1: Gibco) Somerset, UK), penicillin/streptomycin (PAA) and glutamine (PAA). Pyruvate was also added to the medium used for the MC3T3 cells. For the cytoskeletal disruption experiments, either $50 \mu \mathrm{M}$ blebbistatin (Calbiochem, Nottingham, UK) or $50 \mu \mathrm{M}$ Y-27632 (Calbiochem, UK) was added.

\section{Collagen gel preparation}

The preparation of cell-populated dense collagen was carried out as previously described (Brown et al., 2005; Buxton et al., 2008). The final gels were composed of $10 \%$ 10x MEM, $80 \%$ rat-tail collagen type I $(2.10 \mathrm{mg} / \mathrm{mL}$ in $0.6 \%$ acetic acid; $>98 \%$ purity; First Link, Bockmore, UK) and $10 \%$ cell suspension in DMEM. The mixture of MEM and collagen was neutralised by cautious addition of $5 \mathrm{M}$ $\mathrm{NaOH}$ on ice, as determined by a colour change of phenol red (Sigma, Poole, UK). Thereafter, the mixture was mixed gently with the cell suspension to create homogeneity and a pre-compression concentration of $3 \times 10^{5}$ cells $/ \mathrm{mL}$. The solution was poured into a casting reservoir $(2 \mathrm{~mL}$ capacity, $13 \mathrm{~mm} \times 43 \mathrm{~mm}$ ) and allowed to set at room temperature $\left(20{ }^{\circ} \mathrm{C}\right)$ for $30 \mathrm{~min}$. To create a hyper-hydrated collagen gel (HC), the gel was divided into four and incubated in the above-described medium at $37{ }^{\circ} \mathrm{C}$ in $5 \% \mathrm{CO}_{2}$ in air. For production of the dense collagen gel (DC), the set gel was compressed with a one-cycle static stress $(0.5 \mathrm{~N})$ for $5 \mathrm{~min}$ on a bed of absorbent tissue bounded by nylon mesh. This was then processed in a similar manner to the HC.

\section{Cell survival}

To assess cell survival, $10 \% \mathrm{v} / \mathrm{v}$ of alamarBlue ${ }^{\circledR}$ (AbD Serotec, Oxford, UK) was added to each culture well and incubated for $4 \mathrm{~h}$ at $37^{\circ} \mathrm{C}$. Thereafter, $100 \mu \mathrm{L}$ of the supernatant was used for measuring fluorescence, equating to cell metabolic activity, at excitation $530 \mathrm{~nm}$ and emission $590 \mathrm{~nm}$.

\section{Cell morphology and gel contraction}

For analysis of cell morphology, gels were fixed for $10 \mathrm{~min}$ in $4 \%$ paraformaldehyde (PFA) and washed in phosphate-buffered saline (PBS) before cell permeation for 15 min in $0.15 \%$ Triton $^{\mathrm{TM}}$ X-100 (Sigma, UK). Staining for actin and cell nuclei was undertaken by incubation in $0.15 \%$ Triton X-100 with $0.5 \%$ phalloidin (Invitrogen) and $0.1 \%$ ethidium homodimer (Invitrogen) for $15 \mathrm{~min}$. Following mounting with $0.15 \%$ Triton X-100 under a coverslip, confocal imaging was performed with a Biorad confocal system (Biorad, Watford, UK) linked to a Olympus BX51 microscope and LaserSharp 2000 software (Olympus, Southall, UK). 3-D pictures were reconstructed with ImageJ (NIH). Contraction of the gels was captured utilising a Zeiss stereomicroscope.

\section{Cell differentiation}

RNA was extracted from cells within the dense collagen gels using TRIzol ${ }^{\circledR}$ (Invitrogen) in accordance with the manufacturer's guidelines. For mineralised samples, gels were first frozen in liquid $\mathrm{N}_{2}$, crushed in foil using a pestle and mortar, and then processed in TRIzol reagent. cDNA was prepared using a cDNA archive kit (Applied Biosystems, Cheshire, UK), and RT-qPCR was carried out using protocols established for the ABI 7300 RealTime PCR machine (Applied Biosystems). The Taqman $^{\circledR}$ gene expression primer details were as follows: GAPDH, Mm_99999915-g1; ALP(Murshed et al., 2005), Mm_00475831-m1; BSP (Franz-Odendaal et al., 2006), Mm_00492555-m1; Gli1, Mm_00494645-m1. The RTqPCR data obtained were analysed using the Relative Expression Software Tool (REST) (Pfaffl et al., 2002).

\section{Mineralisation}

For assessment of mineralisation, cryosections of unfixed constructs were prepared by embedding the samples in OCT (Raymond Lamb, London, UK), air-dried and stored at $-80{ }^{\circ} \mathrm{C}$ before further analysis. Alkaline phosphatase 


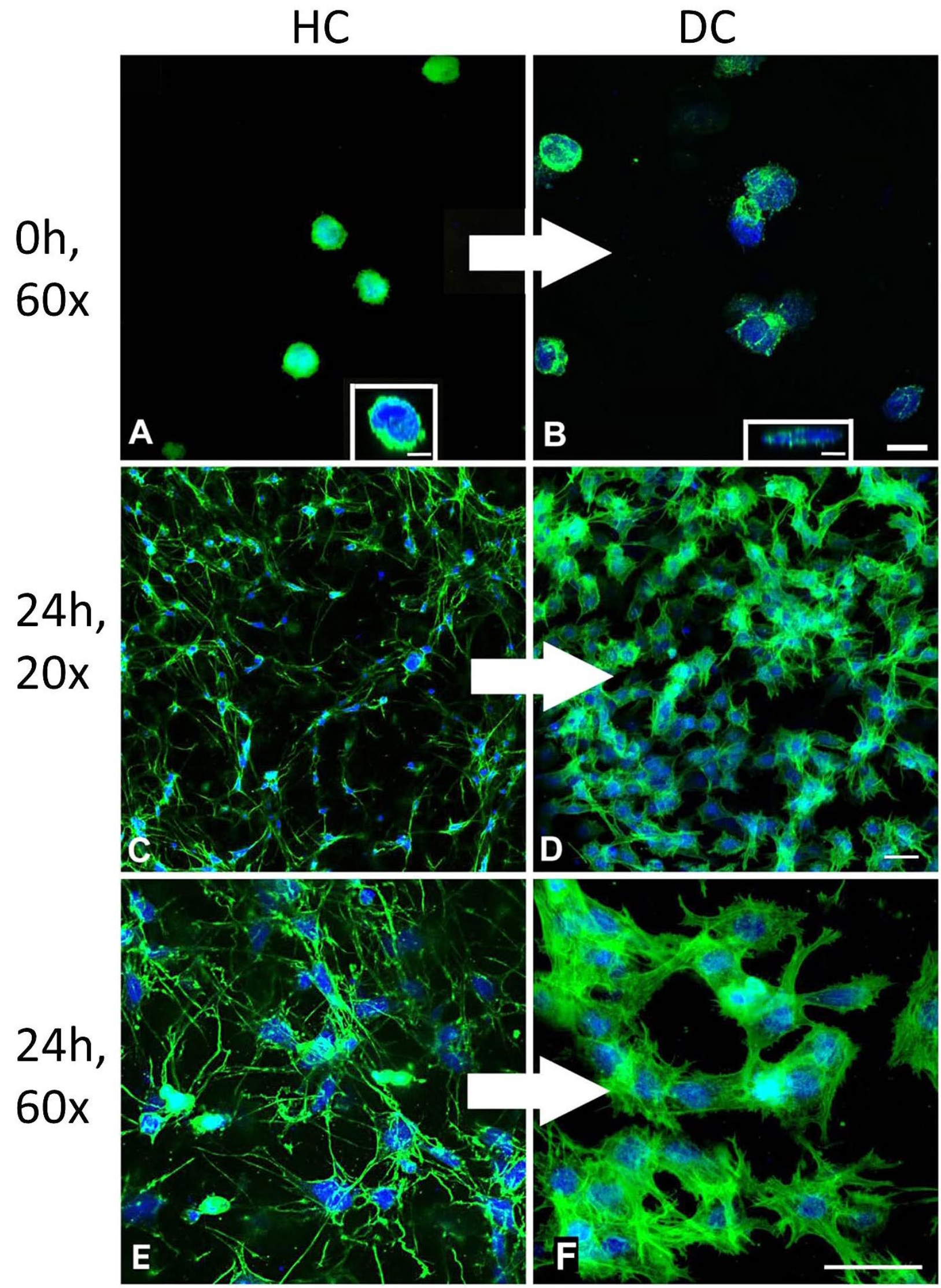

Fig. 1. Confocal images of MC3T3 cells stained with phalloidin and ethidium bromide in hydrated collagen (HC) (0 h: A (20x); 24 h: C (20x) and E (60x)) and in dense collagen (DC) (0 h: B (20x); 24 h: D (20x), F (60x)). A and $\mathbf{B}$ are X-Y images with a Z-stack compilation of one cell showing the effects of compression embedded within the image (Scale bar: $10 \mu \mathrm{m}$ ). 


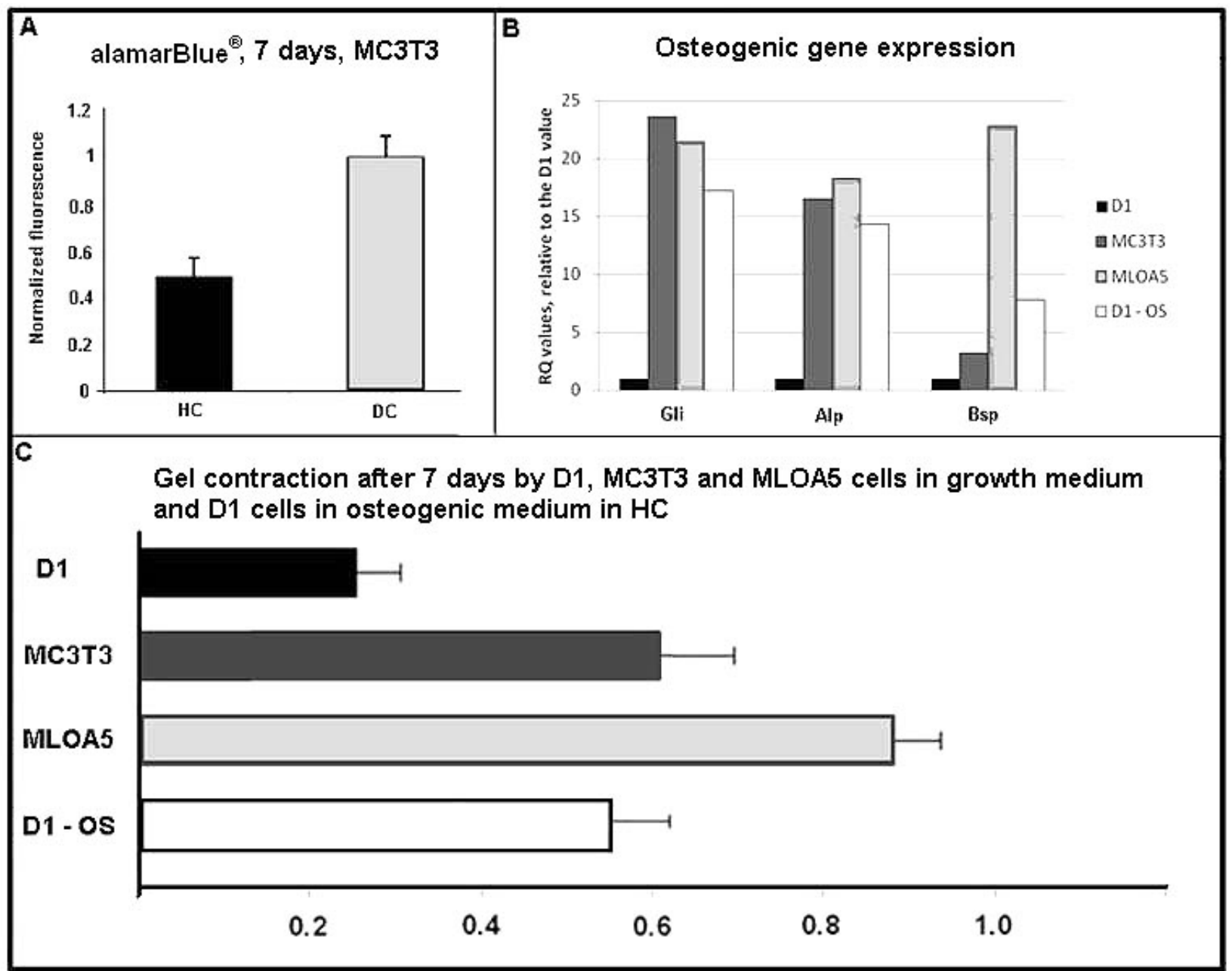

Fig. 2. (A) Cell survival of MC3T3 cells in DC was greater than in $\mathrm{HC}$, as quantified with alamarBlue. (B) Osteogenic gene expression of cells from different differentiation stages: stem-cell like, early osteoblast (D1); osteoblast (MC3T3); late osteoblast, early osteocyte (MLOA5); D1 cells in osteogenic medium (D1-OS). Expression of the osteogenic markers, Gli1, ALP and BSP, was upregulated in all cells types compared to the D1 cells in standard growth medium. (C) Gel contraction varied with the stage of cell differentiation such that with further differentiation there was less contraction. This was confirmed by the reduced contraction effected by D1 cells in osteogenic medium as compared to D1 cells in standard growth medium.

enzyme activity was assessed in situ using Napthol AS-MX and Fast Red Violet LB (Sigma) on post-fixed sections, followed by von Kossa staining using hydroquinone and fixation in sodium thiosulphate. In addition, some of the sections were stained with van Gieson stain.

\section{Tensile testing}

To investigate the change in stiffness of the MC3T3 cellseeded scaffolds with time, tensile testing was undertaken on days 1 and 14. A dynamic mechanical analyser (DMA7e, Perkin-Elmer Instruments, Cambridge, UK) was used to subject the compressed samples to quasi-static uniaxial tension at a rate of $200 \mathrm{mN} / \mathrm{min}$ and data were collected using the Pyris software (Perkin-Elmer).

\section{Results}

Cell morphology and survival in hydrated and dense collagen gels

An obvious, but clear consequence of the gel compression was the increase in relative cell density. The compression also had an effect on cell morphology such that the cells became flattened and changed from a rounded configuration in the hydrated gels to a more ovoid form in the dense gels (Figs. 1A, B). The cells in the hydrated gels were noted to have numerous long extensions and an absence of organised stress fibres (Figs. 1C, E). In contrast, within the dense collagen, the cells had shorter projections and numerous actin filaments forming a close network (Figs. 1D, F), which was comparable to the control. The alamarBlue data at day 7 demonstrated that there was greater metabolic activity, thus implying better cell survival within the dense gels compared to the hydrated gels. There is a suggestion that compression not only leads to a change in cell shape, but also promotes cell survival (Fig. 2A). It is clear that the increase in collagen and cell density did not prevent adequate flow-through of nutrients, perhaps due to the thin nature of the compressed collagen.

The stage of differentiation of the cell types (D1, MC3T3, MLOA5) used within the collagen gels was confirmed by expression of the ALP, BSP and Gli bone genes (Fig. 2B). It was apparent that this stage of differentiation also determined the degree of matrix 


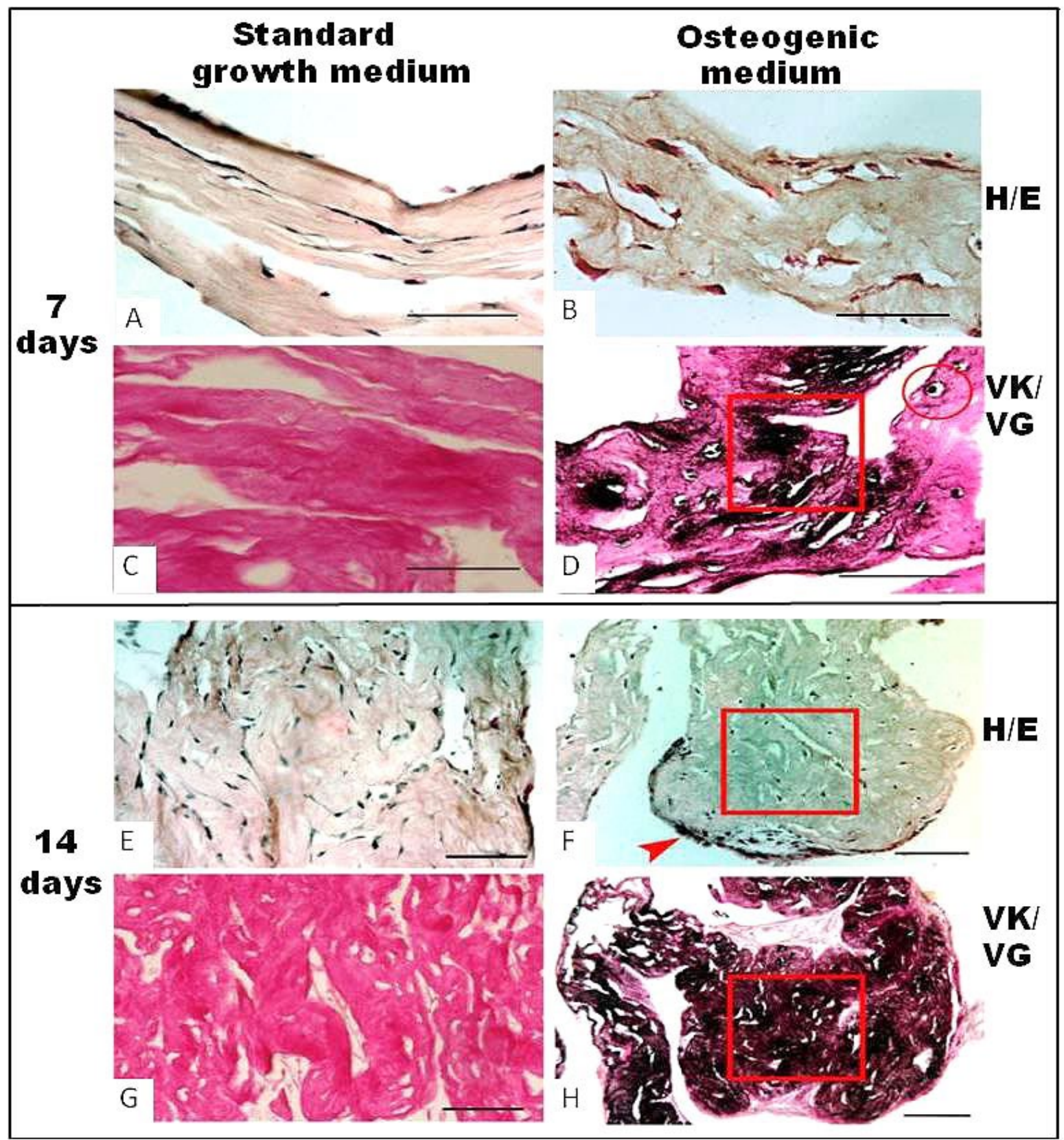

Fig. 3. Dense collagen was used as a delivery vehicle for human MSCs. MSCs were seeded at a pre-compression density of 300,000 cells $/ \mathrm{mL}$ of neutralised collagen. Gels were then compressed and maintained in vitro for $7 \mathrm{~d}$ (A-D) or $14 \mathrm{~d}$ (E-H) in growth medium (A, C, E and $\mathbf{G})$ or osteogenic medium (OS) containing ascorbate and $\beta$-glycerophosphate and dexamethasone (B, D, F and $\mathbf{H})$. Standard wax sections were prepared and stained with haematoxylin/eosin (H/E) or von Kossa/van Gieson (staining collagen pink and mineral black (VK/VG)). Boxed region highlights mineralised collagen after $7 \mathrm{~d}$ in OS (D). After $14 \mathrm{~d}$ in OS, mineralisation is widespread; the same region is boxed in $\mathbf{F}$ and $\mathbf{H}$ with the sparsely populated region now heavily mineralised. Note also the non-mineralised cell layer at the periphery (red arrow, F) (Scale bar: $100 \mu \mathrm{m})$.

contraction, such that D1 cells were associated with the greatest amount of contraction $( \pm 75 \%)$ followed by MC3T3 cells $( \pm 40 \%)$ and MLO-A5 cells ( $\pm 10 \%$ ) (Fig. $2 \mathrm{C}$ ). When osteogenic medium was applied to the D1 cells the gene expression and gel contraction was closer to the more mature bone cell types MC3T3 and MLOA5 (Figs. $2 \mathrm{~B}, \mathrm{C})$. The varying degree of matrix contraction related to the stage of differentiation gives the potential to utilise this property for different tissue engineering applications: above all, it is clear that the use of MSCs allows for greater manipulation in terms of the overall matrix contraction desired and osteogenic expression.

The cells within the gels were incubated in standard growth medium for a period of $7 \mathrm{~d}$, which was then changed to osteogenic medium. After $7 \mathrm{~d}$ in growth medium, cells within DC appeared elongated, following the contours of the collagen and extending within the plane of the compression (Fig. 3A). Incubation in osteogenic 

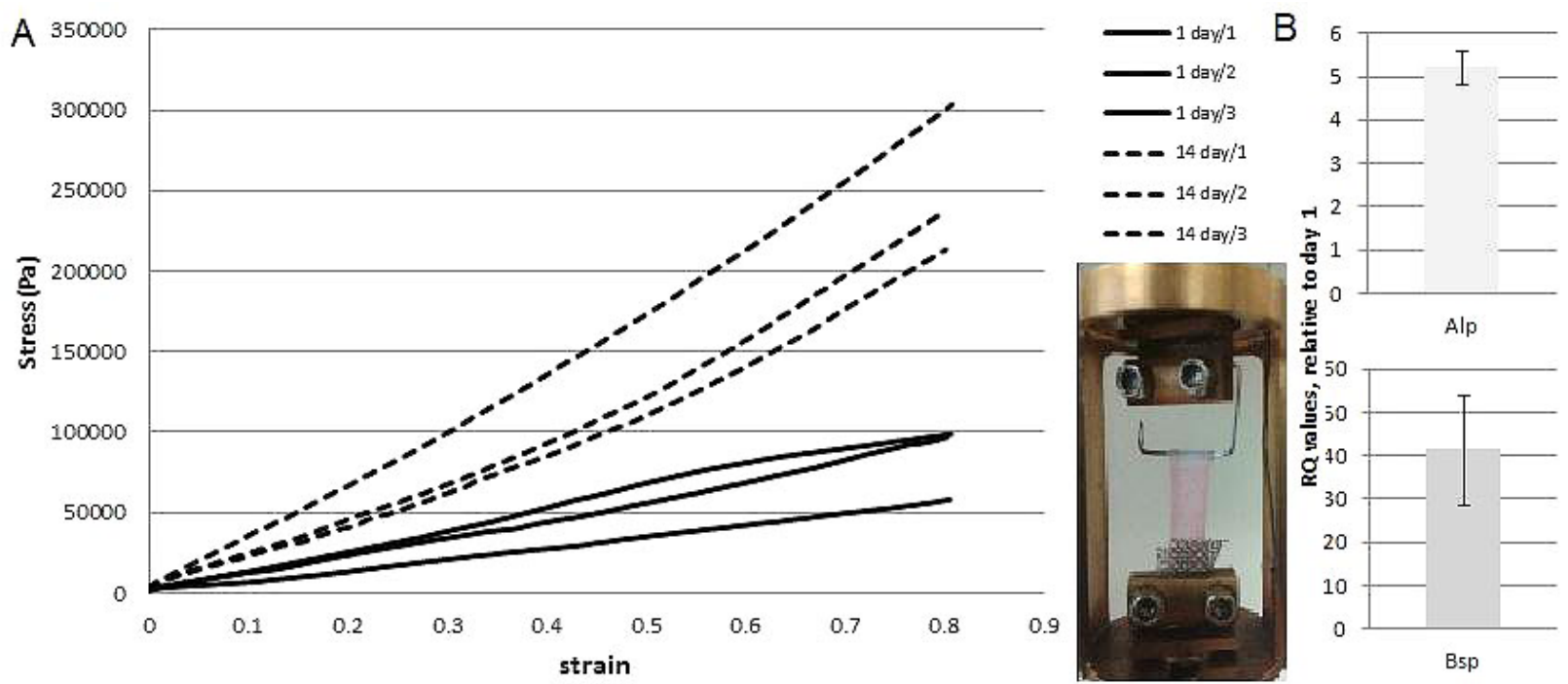

Fig. 4. (A) Stress-strain curve of dense collagen gel measured by stretching the cell-seeded collagen membrane in a dynamic mechanical analyser (inset) after 1 and $14 \mathrm{~d}$ of culture, showing stiffening of the gel over time. (B) Upregulation of ALP and BSP at day 14 in the MC3T3 cells seeded in these dense collagen gels relative to their expression at day 1 .
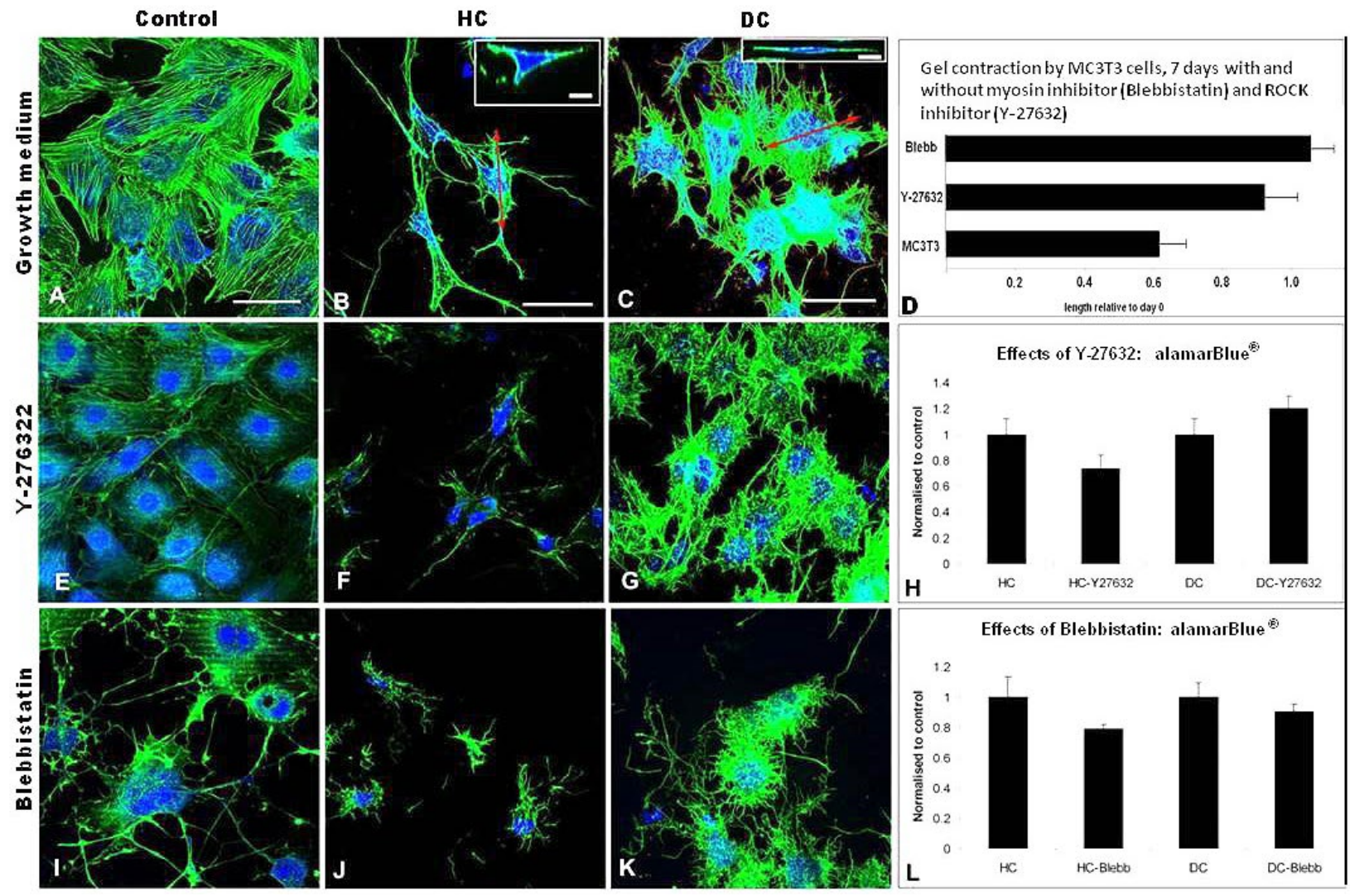

Fig. 5. Confocal images of MC3T3 cells after $24 \mathrm{~h}$ on tissue culture plastic (control) (A, E and I), hydrated collagen (HC) (B, F and $\mathbf{J})$ and dense collagen (DC) $(\mathbf{C}, \mathbf{G}$ and $\mathbf{K})$ (Scale bar: $100 \mu \mathrm{m})$. Cells were either grown in standard growth medium (A-C) or growth medium supplemented with Y-27632 inhibitor (E-G) or blebbistatin inhibitor (I-K). There was less stress fibre disruption of cells within the DC. Disruption of the stress fibres blocked gel contraction (D). However, it is also apparent that the dense collagen promoted cell survival despite the stress fibre inhibition, as confirmed with alamarBlue ( $\mathbf{H}$ and $\mathbf{L})$. 
medium led to the cells remodelling the collagen to form lacunae, which in some cases were occupied by multiple cells (Fig. 3B). Mineralisation was also evident, which became more pronounced with time (Fig. 3: $7 \mathrm{~d}(\mathrm{C} v s . \mathrm{D})$ and $14 \mathrm{~d}(\mathrm{G} v s . \mathrm{H}))$. A dramatic stiffening of the matrix was noted indicating a mechanically improved construct: investigations confirmed that cell-seeded mineralised dense collagen membranes demonstrated by a statistically significant increase in Young's modulus with time (day 1: $105.88 \pm 31.57 \mathrm{MPa}$; day $14: 289.73 \pm 61.02 \mathrm{MPa}$; $<0.01)$ (Fig. 4A). There was also a corresponding increase in expression of the bone-related genes, $A L P$ and $B S P$ (Fig. 4B).

The effect of cytoskeletal (CSK) inhibition was quite profound on the morphology of the control cells, with evidence of complete dissolution of stress fibres when exposed to blebbistatin; the effect was reduced when exposed to the CSK inhibitor, Y-27632 (Fig. 5). In hydrated collagen the effect was similarly dramatic to the control cells with sparse fibres evident and no obvious dendrites and overall fewer numbers of cells (Figs. $5 \mathrm{~A}, \mathrm{E}$ and I $v s$. $\mathrm{B}, \mathrm{F}$ and $\mathrm{J}$ ). On the contrary, cells within the dense collagen gels were still associated with the presence of a network of cytoskeletal fibres, although less so when exposed to blebbistatin (Figs. $5 \mathrm{C}, \mathrm{G}$ and $\mathrm{K}$ ).

The CSK disruption led to a reduction in hydrated collagen gel contraction that corresponded to the cell morphology. On day 7, the degree of contraction effected by cells exposed to Y-27632 was approximately $50 \%$ less than the control. Exposure to blebbistatin completed nullified gel contraction with a small degree of expansion probably due to water imbibition (Fig. 5D). The difference in the effect of the inhibitors on the cells in HC $v s$. DC implied that there was a degree of protection from the dense collagen. This was confirmed by the alamarBlue data (Figs. $5 \mathrm{H}, \mathrm{L})$.

\section{Discussion}

A cell-seeded membrane must possess a number of key qualities if it is to succeed in clinical applications (Liu et al., 2011). It is known that strain stimulates osteoblast function and although this is usually applied as a tensile force, it can also be compressive in nature (Mullender et al., 2004; Sun et al., 2012; Zaman et al., 2000). It was therefore considered that the application of compressive force during the fabrication of cell-seeded collagen gels may promote differentiation through the compression of the cytoskeleton. It has been previously demonstrated that dense compressed collagen has profound effects on osteogenic cells; however, the underlying mechanism was not understood (Buxton et al., 2008). If such a construct is to be successfully and appropriately employed for the engineering or regeneration of tissue, an understanding of the mechanism is mandatory. Therefore, a simple strategy was utilised in this study that aimed to assess the cell response to compression and assess the importance of the cell cytoskeleton for the changes observed. The focus has remained on the influence of the cytoskeleton as the conduit of gel-derived stimuli due to the alteration in the physical environment of the cells rather than the chemical environment (e.g. by the addition of growth factors).

Confocal imaging clearly showed that gel compression does influence the cell's tensegrity, with cytoskeletal disruption differing in hydrated and compressed collagen such that cell survival, differentiation and mineralisation were promoted with a static compressive stress. The tensegrity model links the cytoskeleton to the extracellular matrix, through transmembrane receptors with changes in the extracellular milieu being relayed directly and automatically to the internal structure and vice versa (Janmey, 1998; Katz and Yamada, 1997). Therefore, any stiffening of the external matrix is being reflected in real-time stiffening of the internal cytoskeleton. Both cell survival and osteogenic maturation have been linked to cytoskeletal pre-stress and the rigidity of the substrate, which are both properties modulated by the dense collagen environment (Mansell et al., 2009; Nieponice et al., 2007). Conventionally, one would consider that dense collagen acts to enhance RhoA through flattening of the cell and the provision of a stiff environment, which in turn promotes osteogenic differentiation, as has been demonstrated by experiments on human MSCs (Chen et al., 2011; Hamamura et al., 2012). Thus, one would expect tension within the fibres to be higher within a stiffer matrix, and with the concomitant increase in RhoA. This leads to the suggestion that there would be a greater effect with cytoskeletal fibre disruption of cells in compressed matrices compared to soft matrices (Chen et al., 2011). In this study, it was found that the compressive process diminished the reliance of this pre-stress, as demonstrated by the survival of cells within compressed collagen following exposure to cytoskeletal inhibitors, and the dependency on Rho kinase of cell survival within the soft matrix. It is probable that in dense collagen the integrin-mediated signalling through FAK may be sufficient to maintain survival irrespective of the cytoskeletal response (Shih et al., 2011). Nonetheless, it has been shown that the cytoskeleton is important for osteoblast differentiation with pre-stress being required early on, but not being so influential in the later stages (Wang et al., 2012).

The contractile properties of cells at different stages of differentiation were also investigated in order to identify potential clinical applications. It was clear that bone marrow mesenchymal stem cells promoted the greatest contraction thus providing a relatively stiffer construct for use as a pseudo-periosteum allowing bone regeneration; there was also greater differentiation within the construct with time. The contractile nature of the membrane would allow predictable bridging of large defects protecting the formed haematoma and preventing healing by fibrous intention. Additionally, this study has shown that such a construct promotes cell survival, differentiation and mineralisation, therefore, further supporting bony repair of a defect. The histological investigations of cells within the compressed collagen (Fig. 3) have shown that the cells migrate to the borders of the collagen gel and could provide a source of cells in the area of the defect. Furthermore, the collagen membrane is angiogenic as shown by the attraction of blood vessels when grafted onto a chick chorioallantoic membrane (CAM). 
A dense collagen gel does not possess the ideal tensile properties for use in tendon regeneration or the compressive modulus for use in load-bearing areas of cartilage and bone repair scaffold. Nonetheless, a mesenchymal stem cellseeded dense collagen gel could serve as a substitute for the periosteum, being thin enough to do so and containing migrating progenitor cells. The contractile properties investigated in this paper would help the construct in its potential to be used as a secure barrier membrane in bone regeneration when seeded with osteoprogenitor cells, remaining stretched across a defect site. A cell-free collagen construct would relax and thereby collapse and fail to protect against any ingrowing soft tissue. As the cells start to differentiate, there is a degree of relaxation of the cytoskeleton with the resulting relaxation of the collagen, however, as at this stage the donor cells could be utilised in the repair process. In addition to the above-mentioned properties, biocompatibility and bioresorbability, the construct has been shown to be angiogenic, which is advantageous for bone repair (Kanczler and Oreffo, 2008). Future work will assess the in vivo success in the regeneration of critical-sized defects.

\section{Acknowledgements}

The Authors would like to thank the DfES and the CDRC for their support of this research. This work was supported in part (JCK) by WCU Program through the National Research Foundation of Korea (NRF) funded by the Ministry of Education, Science and Technology (No. R31-10069). We wish to confirm that there are no known conflicts of interest associated with this publication and there has been no significant financial support for this work that could have influenced its outcome.

\section{References}

Abou Neel EA, Cheema U, Knowles JC, Brown RA, Nazhat SN (2006) Use of multiple unconfined compression for control of collagen gel scaffold density and mechanical properties. Soft Matter 2: 986-992.

Bitar M, Salih V, Brown RA, Nazhat SN (2007) Effect of multiple unconfined compression on cellular dense collagen scaffolds for bone tissue engineering. J Mater Sci-Mater Med 18: 237-244.

Bitar M, Brown RA, Salih V, Kidane AG, Knowles JC, Nazhat SN (2008) Effect of cell density on osteoblastic differentiation and matrix degradation of biomimetic dense collagen scaffolds. Biomacromolecules 9: 129-135.

Braddock M, Houston P, Campbell C, Ashcroft P (2001) Born again bone: tissue engineering for bone repair. News Physiol Sci 16: 208-213.

Brown RA, Wiseman M, Chuo CB, Cheema U, Nazhat SN (2005) Ultrarapid engineering of biomimetic materials and tissues: Fabrication of nano- and microstructures by plastic compression. Adv Funct Mater 15: 1762-1770.

Buxton PG, Bitar M, Gellynck K, Parkar M, Brown RA, Young AM, Knowles JC, Nazhat SN (2008) Dense collagen matrix accelerates osteogenic differentiation and rescues the apoptotic response to MMP inhibition. Bone 43: 377-385.

Cai YF, Biais N, Giannone G, Tanase M, Jiang GY, Hofman JM, Wiggins CH, Silberzan P, Buguin A, Ladoux B, Sheetz MP (2006) Nonmuscle myosin IIA-dependent force inhibits cell spreading and drives F-actin flow. Biophys J 91: 3907-3920.

Cheema U, Yang SY, Mudera, V, Goldspink GG, Brown RA (2003) 3-D in vitro model of early skeletal muscle development. Cell Motil Cytoskeleton 54: 226-236.

Cheema U, Chuo CB, Sarathchandra P, Nazhat SN, Brown RA (2007) Engineering functional collagen scaffolds: Cyclical loading increases material strength and fibril aggregation. Adv Func Mater 17: 2426-2431.

Chen ZX, Wang XF, Shao YC, Shi DY, Chen TY, Cui DF, Jiang XX (2011) Synthetic osteogenic growth peptide promotes differentiation of human bone marrow mesenchymal stem cells to osteoblasts via RhoA/ROCK pathway. Mol Cell Biochem 358: 221-227.

Franz-Odendaal TA, Hall BK, Witten PE (2006) Buried alive: How osteoblasts become osteocytes. Dev Dyn 235: 176-190.

Hamamura K, Swarnkar G, Tanjung N, Cho E, Li JL, Na SS, Yokota H (2012) RhoA-mediated signaling in mechanotransduction of osteoblasts. Connect Tissue Res 53: 398-406.

Hu SH, Chen JX, Wang N (2004) Cell spreading controls balance of prestress by microtubules and extracellular matrix. Front Biosci 9: 2177-2182.

Itoh S, Kikuchi M, Takakuda K, Koyama Y, Matsumoto HN, Ichinose S, Tanaka J, Kawauchi T, Shinomiya K (2001) The biocompatibility and osteoconductive activity of a novel hydroxyapatite/collagen composite biomaterial, and its function as a carrier of rhBMP-2. J Biomed Mater Res 54: 445-453.

Jakob M, Saxer F, Scotti C, Schreiner S, Studer P, Scherberich A, Heberer M, Martin, I (2012) Perspective on the evolution of cell-based bone tissue engineering strategies. Eur Surg Res 49: 1-7.

Janmey PA (1998) The cytoskeleton and cell signaling: Component localization and mechanical coupling. Physiol Rev 78: 763-781.

Kanczler JM, Oreffo ROC (2008) Osteogenesis and angiogenesis: The potential for engineering bone. Eur Cell Mater 15: 100-114.

Katz BZ, Yamada KM (1997) Integrins in morphogenesis and signaling. Biochimie 79: 467-476.

Link DP, van den Dolder J, Jurgens WJ, Wolke JG, Jansen, JA (2006) Mechanical evaluation of implanted calcium phosphate cement incorporated with PLGA microparticles. Biomaterials 27: 4941-4947.

Liu SH, Yang RS, Alshaikh R, Lane J. (1995) Collagen in tendon, ligament, and bone healing - A current review. Clin Orthop Relat Res 318: 265-278.

Liu Q, Humpe A, Kletsas D, Warnke F, Becker ST, Douglas T, Sivananthan,S, Warnke PH (2011) Proliferation assessment of primary human mesenchymal stem cells on collagen membranes for guided bone regeneration. Int $\mathrm{J}$ Oral Maxillofac Implants 26: 1004-1010.

Mansell JP, Farrar D, Jones S, Nowghani M (2009) Cytoskeletal reorganisation, 1 alpha,25-dihydroxy vitamin 
D3 and human MG63 osteoblast maturation. Mol Cell Endocrinol 305: 38-46.

Mudera V, Morgan M, Cheema U, Nazhat S, Brown R (2007) Ultra-rapid engineered collagen constructs tested in an in vivo nursery site. J Tissue Eng Regen Med 1: $192-$ 198.

Mullender M, El Haj AJ. Yang Y, van Duin MA, Burger EH, Klein-Nulend J (2004) Mechanotransduction of bone cells in vitro: mechanobiology of bone tissue. Med Biol Eng Comput 42: 14-21.

Murshed M, Harmey D, Millan JL, Mckee MD, Karsenty G (2005) Unique coexpression in osteoblasts of broadly expressed genes accounts for the spatial restriction of ECM mineralization to bone. Genes Dev 19: 1093-1104.

Nieponice A, Maul TM, Cumer JM, Soletti L, Vorp DA (2007) Mechanical stimulation induces morphological and phenotypic changes in bone marrow-derived progenitor cells within a three-dimensional fibrin matrix. J Biomed Mater Res Part A 81A: 523-530.

Olson MF (2004) Contraction reaction: mechanical regulation of Rho GTPase. Trends Cell Biol 14: 111-114.

Perry CR (1999) Bone repair techniques, bone graft, and bone graft substitutes. Clin Orthop Relat Res 360: 71-86.

Pfaffl MW, Horgan GW, Dempfle L. (2002) Relative expression software tool (REST (c)) for group-wise comparison and statistical analysis of relative expression results in real-time PCR. Nucleic Acids Res 30: e36.

Rehfeldt F, Engler AJ, Discher DE (2007) Biomechanics of adult stem cell differentiation guided by matrix elasticity. Biophys J Suppl: 636A.

Rose FR, Oreffo RO (2002) Bone tissue engineering: hope vs. hype. Biochem Biophys Res Commun 292: 1-7.

Shih YRV, Tseng KF, Lai HY, Lin CH, Lee OK (2011) Matrix stiffness regulation of integrin-mediated mechanotransduction during osteogenic differentiation of human mesenchymal stem cells. J Bone Miner Res 26: 730-738.

Stamenovic D, Wang N (2000) Engineering approaches to cytoskeletal mechanics. J Appl Physiol 89: 2085-2090.

Stamenovic D, Mijailovich SM, Tolic-Norrelykke IM, Chen JX, Wang N (2002) Cell prestress. II. Contribution of microtubules. Am J Physiol Cell Physiol 282: C617-C624.

Straight AF, Cheung A, Limouze J, Chen I, Westwood NJ, Sellers JR, Mitchison TJ (2003) Dissecting temporal and spatial control of cytokinesis with a myosin II inhibitor. Science 299: 1743-1747.

Sun XH, McLamore E, Kishore V, Fites K, Slipchenko M, Porterfield, DM, Akkus O (2012) Mechanical stretch induced calcium efflux from bone matrix stimulates osteoblasts. Bone 50: 581-591.
Takahara A, Sugiyama A, Satoh Y, Yoneyama M, Hashimoto K (2003) Cardiovascular effects of Y-27632, a selective Rho-associated kinase inhibitor, assessed in the halothane-anesthetized canine model. Eur J Pharmacol 460: 51-57.

Uehata M, Ishizaki T, Satoh H, Ono T, Kawahara T, Morishita T, Tamakawa H, Yamagami K, Inui J, Maekawa M, Narumiya S (1997) Calcium sensitization of smooth muscle mediated by a Rho-associated protein kinase in hypertension. Nature 389: 990-994.

Wang YK, Yu X, Cohen DM, Wozniak MA, Yang MT, Gao L, Eyckmans J, Chen CS (2012) Bone morphogenetic protein-2-induced signaling and osteogenesis is regulated by cell shape, RhoA/ROCK, and cytoskeletal tension. Stem Cells Dev 21: 1176-1186.

Zaman G, Cheng MZ, Jessop HL, White R, Lanyon LE (2000) Mechanical strain activates estrogen response elements in bone cells. Bone 27: 233-239.

\section{Discussion with Reviewers}

Reviewer I: I would like to ask about migration of the cells from the membrane in an in vivo model. Does it occur, and could it have positive effect on defect regeneration?

Authors: The cells do migrate through the collagen, as shown by Buxton et al. (2008), but we have not seen the cells migrate out of the collagen. In vitro, this could lead to cells growing on the bottom of the 6 well plate, which we have not seen. In vivo, migration out of a well-integrated collagen membrane would be possible, but if autologous cells are used this should not cause a problem.

Reviewer I: Does the collagen swell in vivo, and does this have any impact on cell activity?

Authors: The collagen membranes, once compressed, do not swell in vitro, even after 4 weeks of culture; so, we do not expect the membranes to swell in vivo either.

Reviewer I: Do you test for the purity and composition of the collagen? Could this be a factor that adds to the cell responses?

Authors: We do not test the purity ourselves, but batches are tested at our supplier (FirstLink) where they can guarantee a $>98 \%$ purity. Research should be done on creating similar collagen membranes using human recombinant or bovine collagen, which would be more clinically acceptable. 